\title{
Enhancement of Heat Transfer Using Pins Swimming in Non-Isothermal Fluidic Systems: Exact Solutions
}

\author{
Abdul Rahim A. Khaled \\ King Abdulaziz University, Thermal Engineering and Desalination \\ Technology Department, Saudi Arabia \\ E-mail:akhaled@kau.edu.sa \\ Received April 27, 2011; revised June 20, 2011; accepted June 27, 2011
}

\begin{abstract}
Heat transfer to pins swimming in non-isothermal fluidic systems is theoretically analyzed. Four different cases are considered: [A] pins aligned longitudinally in flowing fluid having constant temperature gradient, [B] pins aligned transversely in flowing fluid flow with constant temperature gradient, [C] pins moving longitudinally towards a heated surface, and [D] pins moving transversely towards the heated surface. The Appropriate unsteady energy transport equations are solved and closed form solutions for the fin temperatures are obtained. Accordingly, different performance indicators are calculated. It is found that heat transfer to the swimming pin increases as the pin thermal length, Peclet number and fluid temperature difference along the pin length increase. It decreases as fluid temperature index along the motion direction increases. Moreover, the swimming pins of case $\mathrm{C}$ are found to produce the maximum system effective thermal conductivity. In addition, pins of case $\mathrm{B}$ with thermal lengths above 11 produce system thermal conductivity independent on the thermal length. Meanwhile, pins of case A having thermal lengths above 10 produce system thermal conductivities less responsive to the thermal length. The system thermal conductivity is noticed to increase as the thermal length and Peclet number increase. Eventually, pins of case D produce system thermal conductivities that are independent on the transverse temperature. Finally, the results of this work provide a basis for modeling super convective fluidic systems that can be used in cooling of electronic components.
\end{abstract}

Keywords: Conduction, Convection, Heat Transfer, Enhancement, Moving Pins

\section{Introduction}

Enhancing heat transfer in thermal systems becomes the primary goal in thermal engineering. This goal can be achieved by various means such as using fins [1-4] and nanofluids [5]. Researchers succeeded to enhance the heat transfer from the finned heated surfaces by several means. For example, many fins configurations such as the slit fins have produced heat transfer coefficient 50 to 100 percent above those of flat fins [6]. Moreover, Yang et al. [7] succeeded to increase the heat transfer rate from a fin-tube heat exchanger by 6.3 percent by optimizing the fin spacing. Sahiti et al. [8] found out that employing interrupted elliptic fins could produce heat transfer coefficient 50 percent above that produced by interrupted circular fins.

Almogbel and Bejan [9] and Almogbel [10] proved that constructal optimization of a fin assembly is capable of producing heat transfer coefficient 500 percent above those of single fin under the same constraints. Li et al. [11] showed that microfinnned helical tubes caused an increase in the heat transfer by 120 percent compared to that of plain tube. Kiwan and Al-Nimr [12] were among the recent researchers who found that using a porous fin with certain porosity might give same performance as conventional fin and save 100 times porosity percent of the fin material. Aldoss et al. [13] found out that the heat transfer through a capsulated liquid metal fins might reach about $500 \%$ above that of an equal-size steel fin. Recently, Khaled $[14,15]$ showed that heat transfer using joint and permeable fins could be $100 \%$ and $40 \%$ above that of typical flat fins, respectively. Moreover, Khaled $[16,17]$ showed that fins with roots and fins with internal flows can increase heat transfer by about $100 \%$ and $200 \%$, respectively, compared flat rootless fins.

Another recent method for enhancing the heat transfer 
from the heated surfaces is by using nanofluids. These are fluids containing suspensions of nanoparticles made of high thermally conductive materials. Nanofluids are noticed to possess large effective thermal conductivities for very low concentrations of nanoparticles. For example, the effective thermal conductivity of ethylene glycol is increased by about $40 \%$ above that of the base fluid when a $0.3 \%$ volume of copper nanoparticles of diameters less than $10 \mathrm{~nm}$ are suspended in the fluid [18]. In addition, Xuan and Li [19] showed that the convective heat transfer coefficient was increased by $60 \%$ for nanofluid composed of water and $2 \% \mathrm{Cu}$-nanoparticles by volume. Finally, the estimated maximum levels of the heat transfer enhancement due to different recent enhancing methods are summarized in the work of Mansoor et al. [20]. Among these methods are utilizing (a) fins and microfins, (b) porous media, (c) large particles suspensions, (d) nanofluids, (e) phase-change devices, (f) flexible seals, (g) flexible complex seals, (h) vortex generators, (i) protrusions, and (j) ultra high thermal conductivity composite materials.

From the previous brief literature survey, it is noticed that many novel ideas were developed recently to enhance the heat transfer from the solid surfaces. In addition, it is proposed in the present work to consider high thermally conductive pins submerged and swimming in the fluid as a new novel method for enhancing the heat transfer from the solid surface. The pin velocities are considered different from the fluid velocity. It is referred to these pins as to "swimming pins". The resulting solid-fluid system is different from the two-phase flow or the nanofluid system [20] by having the pins moving at constant or predetermined velocity. The velocity of the swimming pins can be attained using different methods. Among these methods are: 1) Applying appropriate magnetic forces on the swimming pins along with using magnetized pins, 2) Applying appropriate centrifugal forces on the fluid/suspended-pins system, and 3) Appling appropriate electrostatic forces on the swimming pins along with using electrically charged pins. To the best author knowledge, this proposal has not been discussed before and it is though to be useful for cooling of electronic components.

In this work, four different types of swimming pins are theoretically analyzed. These are the following: [A] Pins swimming longitudinally in flowing fluid having constant temperature gradient, [B] Pins aligned transversely and swimming in flowing fluid having constant temperature gradient, $[\mathrm{C}]$ Pins swimming longitudinally towards a heated surface, and [D] Pins moving transversely towards the heated surface. Such these cases can form a basis for constructing and modeling super convective fluid/swimming-pins systems. Appropriate unsteady en- ergy transport equations are identified and solved theoretically. Closed form solutions for the pin temperature are obtained for each case. Accordingly, different pin performance indicators and the effective thermal conductivity of the fluid/swimming-pins system are computed for the studied cases.

\section{Problem Formulation}

\subsection{Pins Swimming Longitudinally in Flowing Fluid Having Constant Temperature Gradient (Cases A)}

Consider a pin having a uniform cross-sectional area $A_{C}$ and a uniform perimeter $P$. This pin is suspended in flowing fluid inside a heated pipe of diameter $2 r_{o}$. Moreover, the pin is considered to move inside the flowing fluid at a constant velocity $U$. The pin length $L$ which is much larger than its characteristic transverse dimension $L_{C}=A_{C} P$ is taken for this case to be aligned along the $x^{\prime}$-direction as shown in Figure 1. Both $x^{\prime}$ and $U$ have the same direction. Let the pipe be subjected to constant heat flux $q_{s}^{\prime \prime}$ and the mass flow rate of the flowing fluid be $\dot{m}$. As such, the surrounding fluid stream temperature $T_{d}$ inside the pipe can be shown to be equal to the following under fully developed condition:

$$
T_{d}\left(x^{\prime}\right)=T_{d, i}+\frac{q_{s}^{\prime \prime} P_{o}}{\dot{m} c_{p}}\left(x^{\prime}+x\right)
$$

where $P_{o}, c_{p}, T_{d, i}, x^{\prime}$ and $x$ are the pipe perimeter $\left(P_{o}=2 \pi r_{o}\right)$, fluid specific heat, surrounding fluid stream temperature at the inlet, distance between the inlet and the pin left end and the pin coordinate starting from its left end, respectively. The magnitude of $x^{\prime}$ is given by $x^{\prime}=$ $U t$ where $t$ is the time variable. The one-dimensional energy equation applied to the pin can be written in the following form:

$$
\frac{\partial^{2} T_{f}}{\partial x^{2}}-\left(\frac{\rho_{f} c_{f} U}{k_{f}}\right) \frac{\partial T_{f}}{\partial x}-\left(\frac{h P}{k_{f} A_{C}}\right)\left(T_{f}-T_{d}\right)=\left(\frac{\rho_{f} c_{f}}{k_{f}}\right) \frac{\partial T_{f}}{\partial t}
$$

where $T_{f}, \rho_{f}, c_{f}, k_{f}$ and $h$ are the pin temperature, pin density, pin specific heat, pin thermal conductivity and the convection heat transfer between the pin and the surrounding fluid, respectively. Correlations for the $h$-coefficient for each case with sufficient accuracy can be obtained using any recent heat transfer textbooks [21].

Applying the following dimensionless variables:

$$
\begin{aligned}
& x^{*}=\frac{x}{L} ; \\
& t^{*}=\frac{U t}{L} ;
\end{aligned}
$$




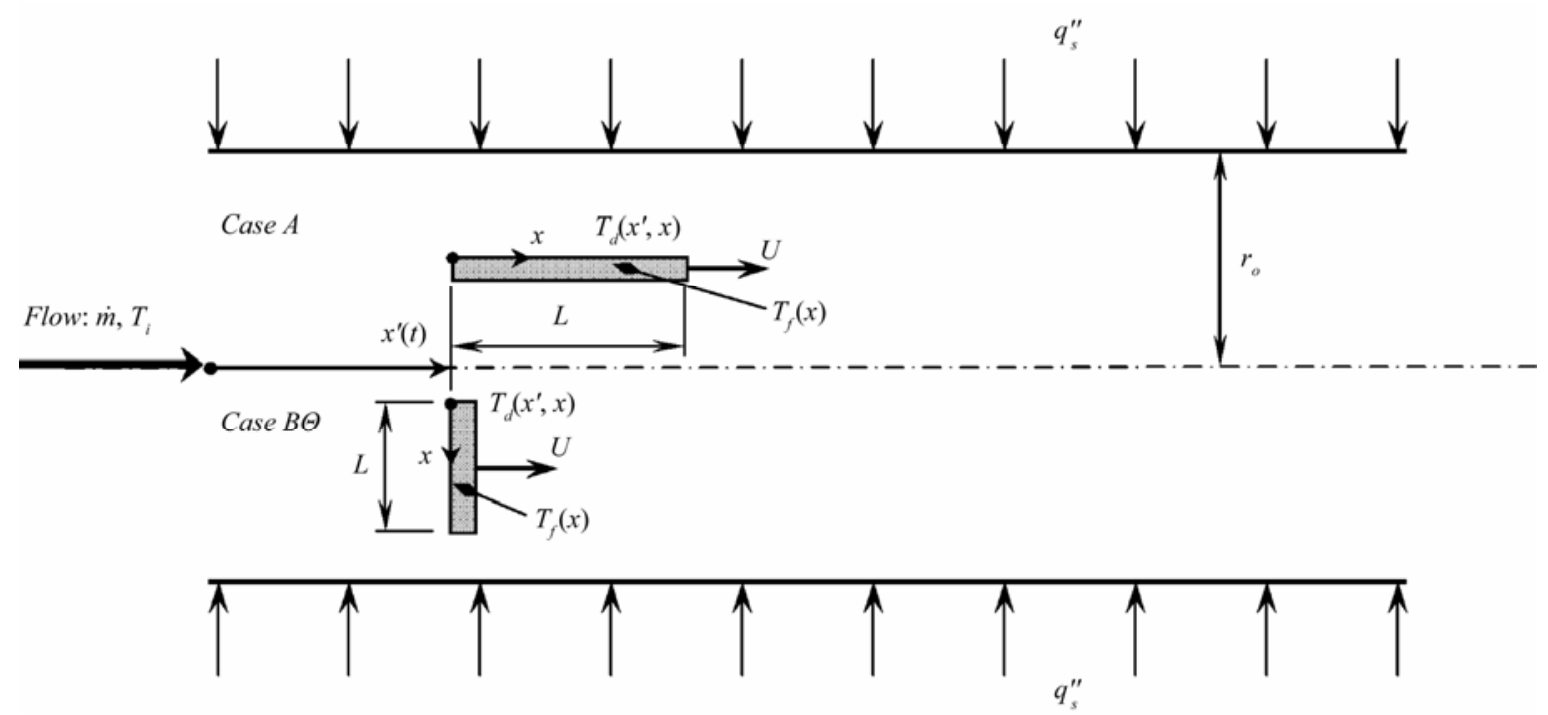

Figure 1. Schematic diagram for swimming pins of cases: A and B, and the flow configurations with coordinates system.

$$
\theta=\frac{T_{f}-T_{d}}{T_{d, i}-T_{d}}
$$

on Equation (2) will change it to the following dimensionless form:

$$
\begin{aligned}
\frac{\partial^{2} \theta}{\partial x^{* 2}} & -\left[P e_{f}-2 \phi_{1}\right] \frac{\partial \theta}{\partial x^{*}}-\left[(m L)^{2}+2 P e_{f} \phi_{1}\right] \theta \\
& +2 P e_{f} \phi_{1}=P e_{f} \frac{\partial \theta}{\partial t^{*}}
\end{aligned}
$$

where $P e_{f}$ (pin Peclet number), $m$ (pin index) and $\phi_{1}$ (characteristic function) are given by

$$
\begin{aligned}
P e_{f} & =\frac{\rho_{f} c_{f} U L}{k_{f}} ; \\
m & =\sqrt{\frac{h P}{k_{f} A_{C}}} ; \\
\phi_{1} & =\frac{1}{x^{*}+t^{*}}
\end{aligned}
$$

The pin is considered to be insulated from both left and right ends. In addition, it is considered to be at temperature $T_{f}=T_{d, i}$ when $t=0$. As such, the dimensionless boundaries and initial conditions are given by

$$
\begin{gathered}
\left.t^{*} \frac{\partial \theta}{\partial x^{*}}\right|_{x^{*}=0, t^{*}}+\theta\left(x^{*}=0, t^{*}\right)=1 ; \\
\left.\left(t^{*}+1\right) \frac{\partial \theta}{\partial x^{*}}\right|_{x^{*}=1, t^{*}}+\theta\left(x^{*}=1, t^{*}\right)=1 ; \\
\theta\left(x^{*}, t^{*}=0\right)=1
\end{gathered}
$$

The net heat transfer rate from the pin to the flowing fluid, $q_{f-d}$, is given by

$$
\begin{aligned}
q_{f-d} & =h P L \int_{0}^{1}\left(T-T_{d}\right) \mathrm{d} x^{*} \\
& =-h P L\left(\frac{q_{s}^{\prime \prime} P_{o} L}{\dot{m} c_{p}}\right) \int_{0}^{1}\left(x^{*}+t^{*}\right) \theta \mathrm{d} x^{*}
\end{aligned}
$$

The temperature increase across any pipe differential element of thickness $L$ which is denoted by $\Delta T_{L}$ is equal to $\Delta T_{L}=q_{s}^{\prime \prime} P_{o} L / \dot{m} c_{p}$. Define the dimensionless pin heat transfer rate $\Theta_{A}$ as the ratio between the pin heat transfer rate to that having maximum temperature difference of $\Delta T_{L}$. Mathematically, it is equal to

$$
\Theta_{A} \equiv \frac{q_{f-d}}{h P L \Delta T_{L}}=-\int_{0}^{1}\left(x^{*}+t^{*}\right) \theta \mathrm{d} x^{*}
$$

\section{Closed Form Solutions}

Define the variable $g\left(x^{*}, t^{*}\right)$ as the following:

$$
g\left(x^{*}, t^{*}\right)=\left(x^{*}+t^{*}\right) \theta\left(x^{*}, t^{*}\right)
$$

Substituting Equation (9) in Equation (4) results in the following form of energy equation:

$$
\frac{\partial^{2} g}{\partial x^{* 2}}-P e_{f} \frac{\partial g}{\partial x^{*}}-(m L)^{2} g+2 P e_{f}=P e_{f} \frac{\partial g}{\partial t^{*}}
$$

The boundaries and initial conditions are obtained by substituting Equation (9) in Equations (6a-c). As such, the boundary and initial conditions of $g\left(x^{*}, t^{*}\right)$ are given by

$$
\begin{aligned}
& \left.\frac{\partial g}{\partial x^{*}}\right|_{x^{*}=0}=\left.\frac{\partial g}{\partial x^{*}}\right|_{x^{*}=1}=1 \\
& g\left(x^{*}, t^{*}=0\right)=x^{*}
\end{aligned}
$$


The solution of $g\left(x^{*}, t^{*}\right)$ can be decomposed into sum of two solutions: 1) the steady state solution $g_{s A}\left(x^{*}\right)$ and, 2) the homogenous solution $\psi_{A}\left(x^{*}, t^{*}\right)$. The corresponding governing equations for each one are taken to be

$$
\begin{aligned}
& \frac{\mathrm{d}^{2} g_{s A}}{\mathrm{~d} x^{* 2}}-P e_{f} \frac{\mathrm{d} g_{s A}}{\mathrm{~d} x^{*}}-(m L)^{2} g_{s A}+2 P e_{f}=0 \\
& \frac{\partial^{2} \psi_{A}}{\partial x^{* 2}}-P e_{f} \frac{\partial \psi_{A}}{\partial x^{*}}-(m L)^{2} \psi_{A}=P e_{f} \frac{\partial \psi_{A}}{\partial t^{*}}
\end{aligned}
$$

The corresponding boundary and initial conditions are taken to be

$$
\begin{aligned}
& \left.\frac{\mathrm{d} g_{s A}}{\mathrm{~d} x^{*}}\right|_{x^{*}=0}=\left.\frac{\mathrm{d} g_{S A}}{\mathrm{~d} x^{*}}\right|_{x^{*}=1}=1 ; \\
& \left.\frac{\partial \psi_{A}}{\partial x^{*}}\right|_{x^{*}=0, t^{*}}=\left.\frac{\partial \psi_{A}}{\partial x^{*}}\right|_{x^{*}=1, t^{*}}=0 ; \\
& \psi_{A}\left(x^{*}, t^{*}=0\right)=x^{*}-g_{S A}\left(x^{*}\right)
\end{aligned}
$$

Utilizing the theory of ordinary differential equations, separation of variables and the Sturm-Liouville theory [17], the following solutions can be obtained:

$$
\begin{aligned}
g_{\mathrm{sA}}\left(x^{*}\right) & =C_{1} \exp \left(s_{1} x^{*}\right)+C_{2} \exp \left(s_{2} x^{*}\right)+A_{1} \\
\psi_{A}\left(x^{*}, t^{*}\right)= & E_{a} \exp \left(-\left[\frac{(m L)^{2}}{P e_{f}}\right] t^{*}\right) \\
& +\exp \left(-\left[\frac{(m L)^{2}}{P e_{f}}+\frac{P e_{f}}{4}\right] t^{*}\right) \\
& \times \sum_{n=1}^{\infty} E_{n} \exp \left(\frac{P e_{f} x^{*}}{2}-\frac{n^{2} \pi^{2} t^{*}}{P e_{f}}\right) X_{n}\left(n \pi x^{*}\right)
\end{aligned}
$$

where $A_{1}, C_{1}, C_{2}, s_{1}$ and $s_{2}$ are equal to

$$
\begin{gathered}
A_{1}=\frac{2 P e_{f}}{(m L)^{2}} ; \\
C_{1}=\frac{\exp \left(s_{2}\right)-1}{s_{1}\left(\exp \left(s_{2}\right)-\exp \left(s_{1}\right)\right)} ; \\
C_{2}=\frac{1-\exp \left(s_{1}\right)}{s_{2}\left(\exp \left(s_{2}\right)-\exp \left(s_{1}\right)\right)} ; \\
S_{1}=\frac{P e_{f}}{2}-\sqrt{\frac{P e_{f}^{2}}{4}+(m L)^{2}} ; \\
s_{2}=\frac{P e_{f}}{2}+\sqrt{\frac{P e_{f}^{2}}{4}+(m L)^{2}}
\end{gathered}
$$

The functions $X_{n}\left(n \pi x^{*}\right)$ are equal to

$$
X_{n}\left(n \pi x^{*}\right)=\cos \left(n \pi x^{*}\right)-\left(\frac{P e_{f}}{2 n \pi}\right) \sin \left(n \pi x^{*}\right)
$$

The constants $E_{a}$ and $E_{n}$ 's are equal to

$$
\begin{aligned}
E_{a}= & \left\{\frac{1}{P e_{f}}-A_{1}\right\}-\left\{\frac{1}{\exp \left(P e_{f}\right)-1}\right\} \\
& +\sum_{m=1}^{2}\left\{\frac{\exp \left(P e_{f}\right)-\exp \left(s_{m}\right)}{\exp \left(P e_{f}\right)-1}\right\}\left(\frac{C_{m} P e_{f}}{s_{m}-P e_{f}}\right) \\
E_{n}= & \frac{\left\{\exp \left(-\frac{P e_{f}}{2}\right)(-1)^{n}-1\right\}}{\left(\frac{1}{2 n^{2} \pi^{2}}\right)\left(\frac{P e_{f}^{2}}{4}+n^{2} \pi^{2}\right)^{2}} \\
& \left.-\sum_{m=1}^{2} \frac{2 n^{2} \pi^{2} C_{m} s_{m}\left\{\exp \left(s_{m}-\frac{P e_{f}}{2}\right)(-1)^{n}-1\right\}}{4}+n^{2} \pi^{2}\right)\left\{\left[s_{m}-\frac{P e_{f}}{2}\right]^{2}+n^{2} \pi^{2}\right\}
\end{aligned}
$$
to

As such, the dimensionless heat transfer rate is equal

$$
\begin{aligned}
\Theta_{A}= & -A_{1}+\frac{C_{1}}{s_{1}}\left(1-\exp \left(s_{1}\right)\right)+\frac{C_{2}}{s_{2}}\left(1-\exp \left(s_{2}\right)\right) \\
& -E_{a} \exp \left(-\left[\frac{(m L)^{2}}{P e_{f}}\right] t^{*}\right)-P e_{f} \\
& \times \exp \left(-\left[\frac{(m L)^{2}}{P e_{f}}+\frac{P e_{f}}{4}\right] t^{*}\right) \\
& \times \sum_{n=1}^{\infty} E_{n} \exp \left(-\frac{n^{2} \pi^{2} t^{*}}{P e_{f}}\right)\left(\frac{\exp \left(\frac{P e_{f}}{2}\right)(-1)^{n}-1}{\frac{P e_{f}^{2}}{4}+n^{2} \pi^{2}}\right)
\end{aligned}
$$

The maximum effective swimming pin index denoted by $m_{\infty}$ can be obtained by solving the following equation: $\left.q_{f-d}\right|_{m=m_{\infty}}=\left.0.99 q_{f-d}\right|_{m \rightarrow \infty}$. As such, $m_{\infty} L$ for this case is obtained by solving the following equation:

$$
s^{*}\left\{\sinh \left(P e_{f} / 2\right)+\cosh \left(s^{*}\right)\right\}=0.01\left(m_{\infty} L\right)^{2} \sinh \left(s^{*}\right)
$$

where $s^{*}=\sqrt{\left(m_{\infty} L\right)^{2}+P e_{f}^{2} / 4}$. Note that the maximum heat transfer rate is equal to 
$\left.q_{f-d}\right|_{m \rightarrow \infty}=-2 k_{f} A_{C} \Delta T_{L} P e_{f} / L=-2 \rho_{f} c_{f} A_{C} U \Delta T_{L}$.

\subsection{Pins Aligned Transversely and Swimming in Flowing Fluid Having Constant Temperature Gradient (Cases B)}

Let the pin described in section 2.1 be aligned transversely such that the pin centerline is normal to the $U$-direction as shown in Figure 1. The fluid temperature around the pin can be approximated by the following expression:

$$
T_{d}\left(x^{\prime}\right)=T_{i}+\Delta T_{d}\left(\frac{x}{L}\right)+\left(\frac{q_{s}^{\prime \prime} P_{o}}{\dot{m} c_{p}}\right) U t
$$

where $\Delta T_{d}$ is the fluid undisturbed stream temperature increase across the pin length. Define the dimensionless time according to the following:

$$
t^{*}=\left(\frac{k_{f}}{\rho_{f} c_{f}}\right)\left[\frac{t}{L^{2}}\right]
$$

According to Equation (23) and Equation (3a), Equation (22) changes to

$$
T_{d}\left(x^{*}, t^{*}\right)=T_{i}+\Delta T_{d} x^{*}+\Delta T_{L} P e_{f} t^{*}
$$

The one-dimensional energy equation applied to the pin for this case has the following form:

$$
\frac{\partial^{2} T_{f}}{\partial x^{2}}-\left(\frac{h P}{k_{f} A_{C}}\right)\left(T_{f}-T_{d}\right)=\left(\frac{\rho_{f} c_{f}}{k_{f}}\right) \frac{\partial T_{f}}{\partial t}
$$

Utilizing the dimensionless variables given by Equation (3a,c) and Equation (23), Equation (25) can be changed to the following dimensionless form:

$$
\frac{\partial^{2} \theta}{\partial x^{* 2}}+2 \phi_{2} \frac{\partial \theta}{\partial x^{*}}-\left[(m L)^{2}+\lambda_{1} \phi_{2}\right] \theta=\frac{\partial \theta}{\partial t^{*}}
$$

where $\phi_{2}$ (characteristic function) and $\lambda_{1}$ (Temperature difference ratio) are given by

$$
\begin{aligned}
& \phi_{2}=\frac{1}{x^{*}+\lambda_{1} t^{*}} ; \\
& \lambda_{1}=\left(\frac{\Delta T_{L}}{\Delta T_{d}}\right) P e_{f}
\end{aligned}
$$

The dimensionless boundaries and initial conditions as adopted in section 2.1 can be expressed in the following dimensionless forms:

$$
\left.\lambda_{1} t^{*} \frac{\partial \theta}{\partial x^{*}}\right|_{x^{*}=0, t^{*}}+\theta\left(x^{*}=0, t^{*}\right)=1
$$

$$
\begin{gathered}
\left.\left(\lambda_{1} t^{*}+1\right) \frac{\partial \theta}{\partial x^{*}}\right|_{x^{*}=1, t^{*}}+\theta\left(x^{*}=1, t^{*}\right)=1 ; \\
\theta\left(x^{*}, t^{*}=0\right)=1
\end{gathered}
$$

The heat transfer from the pin to the flowing fluid is given by

$$
\begin{aligned}
q_{f-d} & =h P L \int_{0}^{1}\left(T-T_{d}\right) \mathrm{d} x^{*} \\
& =-h P L \Delta T_{d} \int_{0}^{1}\left(x^{*}+\lambda_{1} t^{*}\right) \theta \mathrm{d} x^{*}
\end{aligned}
$$

Define the dimensionless pin heat transfer rate $\Theta_{B}$ as the ratio between the pin heat transfer rate to that having maximum temperature difference of $\Delta T_{d}$. Mathematically, it is equal to

$$
\Theta_{B} \equiv \frac{q_{f-d}}{h P L \Delta T_{d}}=-\int_{0}^{1}\left(x^{*}+\lambda_{1} t^{*}\right) \theta \mathrm{d} x^{*}
$$

\section{Closed Form Solutions}

Redefine the variable $g\left(x^{*}, t^{*}\right)$ as the following:

$$
g\left(x^{*}, t^{*}\right)=\left(x^{*}+\lambda_{1} t^{*}\right) \theta\left(x^{*}, t^{*}\right)
$$

Substituting Equation (31) in Equation (25) results in the following dimensionless form of the energy equation:

$$
\frac{\partial^{2} g}{\partial x^{* 2}}-(m L)^{2} g=P e_{f} \frac{\partial g}{\partial t^{*}}
$$

The boundaries and initial conditions are obtained by substituting Equation (31) in Equations (28a-c). They are given by Equations (11a-c). The equations for the steady state and homogenous solutions are given by

$$
\begin{aligned}
& \frac{\mathrm{d}^{2} g_{s B}}{\mathrm{~d} x^{* 2}}-(m L)^{2} g_{s B}=0 \\
& \frac{\partial^{2} \psi_{B}}{\partial x^{* 2}}-(m L)^{2} \psi_{B}=\frac{\partial \psi_{B}}{\partial t^{*}}
\end{aligned}
$$

The corresponding boundary and initial conditions are given by Equations (14a-c). Utilizing the theory of ordinary differential equations, separation of variables and the Sturm-Liouville theory [22], the following solutions can be obtained.

$$
\begin{gathered}
g_{s B}\left(x^{*}\right)=\frac{\cosh \left(m L x^{*}\right)-\cosh \left(m L\left[1-x^{*}\right]\right)}{(m L) \sinh (m L)} \\
\psi_{B}\left(x^{*}, t^{*}\right)=\exp \left(-[m L]^{2} t^{*}\right) \sum_{n=1}^{\infty} F_{n} \exp \left(-n^{2} \pi^{2} t^{*}\right) \cos \left(n \pi x^{*}\right)
\end{gathered}
$$

The coefficients $F_{n}$ are equal to

$$
F_{n}=2\left\{\frac{(-1)^{n}-1}{n^{2} \pi^{2}}\right\}-\left\{\frac{(-1)^{n}-1}{[m L]^{2}+n^{2} \pi^{2}}\right\}
$$


As such, the dimensionless heat transfer rate is equal to

$$
\Theta_{B}=-\exp \left(-(m L)^{2} t^{*}\right) \sum_{n=1}^{\infty} F_{n} \exp \left(-n^{2} \pi^{2} t^{*}\right)\left\{\frac{(-1)^{n}-1}{n^{2} \pi^{2}}\right\}
$$

The steady state value of $\Theta_{B}$ is zero. According to Equation (35), the pin base section is located at $x^{*}=0.5$ where the convection heat transfer changes its direction at this section. Therefore, the maximum conduction heat transfer rate through this pin is obtained from the following mathematical relationship:

$$
\begin{aligned}
q_{f} & =-\left.k_{f}\left(\frac{A_{C}}{L}\right) \frac{\partial T_{f}}{\partial x^{*}}\right|_{x^{*}=0.5} \\
& =k_{f}\left(\frac{A_{C}}{L}\right) \Delta T_{d}\left\{\frac{1}{\cosh (m L / 2)}-1\right\}
\end{aligned}
$$

As such, the pin maximum dimensionless conduction heat transfer denoted by $\gamma$ is equal to

$$
\gamma \equiv \frac{q_{f}}{-h P L \Delta T_{d}}=\frac{1}{(m L)^{2}}\left\{1-\frac{1}{\cosh (m L / 2)}\right\}
$$

The effective swimming pin length denoted by $L_{\infty}$ can be obtained by solving the following equation:

$\left.\left(q_{f}\right)\right|_{L=L_{\infty}}=\left.0.99\left(q_{f}\right)\right|_{L \rightarrow \infty}$. As such, $m L_{\infty}$ can be shown to be $m L_{\infty}=10.597$.

\subsection{Pins Swimming Longitudinally Towards a Heated Surface (Cases C)}

Let the pin described in section 2.1 be moving towards a hot surface with temperature $T_{s}$ at a constant velocity $U$ as shown in Figure 2. The fluid stream temperature surrounding the pin can be approximated by the following expression:

$$
T_{d}\left(x^{\prime}\right)=T_{\infty}+\left(T_{s}-T_{\infty}\right) \exp \left(-b\left[x^{\prime}-x\right]\right)
$$

where $T_{\infty}, b, x^{\prime}$ and $x$ are the fluid far stream temperature, positive quantity, the position vector of the pin upper end and the pin axial coordinate starting from the pin upper end, respectively. The position vector $x^{\prime}$ is a time dependent quantity given by $x^{\prime}=x_{o}-U t$ where $t$ is the time variable. In terms of dimensionless variables given by Equation (3a,b), Equation (41) changes to

$$
T_{d}\left(x^{*}, t^{*}\right)=T_{\infty}+\left(T_{s}-T_{\infty}\right) C \exp \left(B\left[x^{*}+t^{*}\right]\right)
$$

where $B$ and $C$ are equal to

$$
\begin{gathered}
B=b L ; \\
C=\exp \left(-b x_{o}\right)
\end{gathered}
$$

According to Equation (41), the dimensionless time

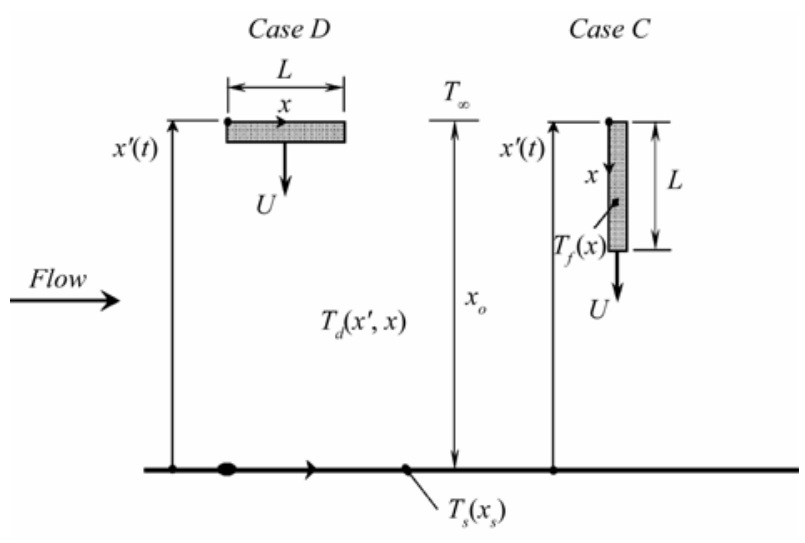

Figure 2. Schematic diagram for swimming pins of cases: $\mathbf{C}$ and $D$, and the flow configurations with coordinates system.

required for the pin to reach the heated surface is equal to $t_{f}^{*}=x_{o} / L-1$. Redefining Equation (3c) as

$$
\theta\left(x^{*}, t^{*}\right)=\frac{T\left(x^{*}, t^{*}\right)-T_{d}\left(x^{*}, t^{*}\right)}{T_{\infty}-T_{d}\left(x^{*}, t^{*}\right)}
$$

Applying the dimensionless variables given by Equation (3a,b) and Equation (44) on Equation (2) will change it to the following dimensionless form:

$$
\begin{aligned}
& \frac{\partial^{2} \theta}{\partial x^{* 2}}-\left[P e_{f}-2 B\right] \frac{\partial \theta}{\partial x^{*}}-\left[(m L)^{2}+2 P e_{f} B-B^{2}\right] \theta-B^{2} \\
& +2 B P e_{f}=P e_{f} \frac{\partial \theta}{\partial t^{*}}
\end{aligned}
$$

The dimensionless boundaries and initial conditions as adopted in section 2.1 can be expressed in the following dimensionless forms:

$$
\begin{gathered}
\left.\frac{\partial \theta}{\partial x^{*}}\right|_{x^{*}=0, t^{*}}+B \theta\left(x^{*}=0, t^{*}\right)=B ; \\
\left.\frac{\partial \theta}{\partial x^{*}}\right|_{x^{*}=1, t^{*}}+B \theta\left(x^{*}=1, t^{*}\right)=B ; \\
\theta\left(x^{*}, t^{*}=0\right)=1
\end{gathered}
$$

The heat transfer from the pin to the flowing fluid is given by

$$
\begin{aligned}
q_{f-d} & =h P L \int_{0}^{1}\left(T-T_{d}\right) \mathrm{d} x^{*} \\
& =-h P L\left(T_{s}-T_{\infty}\right) C \int_{0}^{1} \exp \left(B\left[x^{*}+t^{*}\right]\right) \theta \mathrm{d} x^{*}
\end{aligned}
$$

Define the dimensionless pin heat transfer rate $\Theta_{C}$ as the ratio between the pin heat transfer rate to that having maximum temperature difference of $\Delta T=\left(T_{s}-T_{\infty}\right)$. Mathematically, it is equal to 


$$
\Theta_{C} \equiv \frac{q_{f-d}}{h P L \Delta T}=-C \int_{0}^{1} \exp \left(B\left[x^{*}+t^{*}\right]\right) \theta \mathrm{d} x^{*}
$$

\section{Closed Form Solutions}

The solution of $\theta\left(x^{*}, t^{*}\right)$ can be decomposed into sum of two solutions: 1) the steady state solution $\theta_{s C}\left(x^{*}\right)$ and, 2) the homogenous solution $\psi_{C}\left(x^{*}, t^{*}\right)$. The corresponding governing equations for each one are taken to be

$$
\begin{aligned}
& \frac{\mathrm{d}^{2} \theta_{s C}}{\mathrm{~d} x^{* 2}}-\left[P e_{f}-2 B\right] \frac{\mathrm{d} \theta_{s C}}{\mathrm{~d} x^{*}}-\left[(m L)^{2}+2 P e_{f} B-B^{2}\right] \theta_{s C} \\
& -B^{2}+2 B P e_{f}=0 \\
& \frac{\partial^{2} \psi_{C}}{\partial x^{* 2}}-\left[P e_{f}-2 B\right] \frac{\partial \psi_{C}}{\partial x^{*}}-\left[(m L)^{2}+2 P e_{f} B-B^{2}\right] \psi_{C} \\
& =P e_{f} \frac{\partial \psi_{C}}{\partial t^{*}}
\end{aligned}
$$

The corresponding boundary and initial conditions are taken to be

$$
\begin{aligned}
& \left.\frac{\mathrm{d} \theta_{S C}}{\mathrm{~d} x^{*}}\right|_{x^{*}=0}+B \theta_{S C}\left(x^{*}=0\right)=B ; \\
& \left.\frac{\mathrm{d} \theta_{s}}{\mathrm{~d} x^{*}}\right|_{x^{*}=1}+B \theta_{S C}\left(x^{*}=1\right)=B ; \\
& \left.\frac{\partial \psi_{C}}{\partial x^{*}}\right|_{x^{*}=0, t^{*}}+B \psi_{C}\left(x^{*}=0, t^{*}\right)=0 ; \\
& \left.\frac{\partial \psi_{C}}{\partial x^{*}}\right|_{x^{*}=1, t^{*}}+B \psi_{C}\left(x^{*}=1, t^{*}\right)=0 ; \\
& \psi_{C}\left(x^{*}, t^{*}=0\right)=1-\theta_{s C}\left(x^{*}\right)
\end{aligned}
$$

According to Equation (48), $\Theta_{C}$ is always increasing with time. The maximum value of $\Theta_{C}$ which is denoted by $\left(\Theta_{C}\right)_{\max }$ is of special importance to this work. It is equal to $\Theta_{C}$ at the maximum available dimensionless time $\left(t_{f}^{*}=x_{o} / L-1\right)$. At that time, $\theta\left(x^{*}, t^{*}\right)$ is expected to be equal to $\theta_{s C}\left(x^{*}\right)$. The solution of $\theta_{s C}\left(x^{*}\right)$ as obtained from solving Equation (49) is equal to

$$
\theta_{s C}\left(x^{*}\right)=C_{5} \exp \left(s_{5} x^{*}\right)+C_{6} \exp \left(s_{6} x^{*}\right)+A_{2}
$$

where $A_{2}, \mathrm{C}_{5}, C_{6}, s_{5}$ and $s_{6}$ are equal to

$$
\begin{gathered}
A_{2}=\frac{2 B P e_{f}-B^{2}}{(m L)^{2}+2 B P e_{f}-B^{2}} ; \\
C_{5}=\left\{\frac{1-A_{2}}{s_{5}+B}\right\}\left\{\frac{\exp \left(s_{6}\right)-1}{\exp \left(s_{6}\right)-\exp \left(s_{5}\right)}\right\} B ;
\end{gathered}
$$

$$
\begin{aligned}
& C_{6}=\left\{\frac{1-A_{2}}{s_{6}+B}\right\}\left\{\frac{1-\exp \left(s_{5}\right)}{\exp \left(s_{6}\right)-\exp \left(s_{5}\right)}\right\} B ; \\
& S_{5}=\left(\frac{P e_{f}}{2}-B\right)-\sqrt{\frac{P e_{f}^{2}}{4}+P e_{f} B+(m L)^{2}} ; \\
& S_{6}=\left(\frac{P e_{f}}{2}-B\right)+\sqrt{\frac{P e_{f}^{2}}{4}+P e_{f} B+(m L)^{2}}
\end{aligned}
$$

As such, $\left(\Theta_{C}\right)_{\max }$ is equal to

$$
\begin{aligned}
\left(\Theta_{C}\right)_{\max }= & \left\{\frac{\exp (-B)-\exp \left(s_{5}\right)}{s_{5}+B}\right\} C_{5} \\
& +\left\{\frac{\exp (-B)-\exp \left(s_{6}\right)}{s_{6}+B}\right\} C_{6} \\
& +A_{2}\left\{\frac{\exp (-B)-1}{B}\right\}
\end{aligned}
$$

Note that the maximum heat transfer rate can be obtained and it is equal to $\left.q_{f-d}\right|_{m \rightarrow \infty}=2 \rho_{f} c_{f} A_{C} U\left(T_{s}-T_{\infty}\right)(\exp (-B)-1)$. Since $m_{\infty}$ can be obtained by solving the following equation: $\left.q_{f-d}\right|_{m=m_{\infty}}=\left.0.99 q_{f-d}\right|_{m \rightarrow \infty}$. It is the solution of

$$
\left.\left(m_{\infty} L\right)^{2}\left(\Theta_{C}\right)_{\max }\right|_{m=m_{\infty}}=1.98 P e_{f}(\exp (-B)-1)
$$

\subsection{Pins Moving Transversely Towards the Heated Surface (Cases D)}

Let the pin described in section 2.3 be aligned transversely and be moving at a constant velocity $U$ towards the hot surface as shown in Figure 2. The heated surface temperature is considered to be varying exponentially with $x_{s}$-axis that is coinciding with pin axial axis. This variation is according to the following relationship:

$$
T_{s}(x)-T_{\infty}=\left(T_{\text {so }}-T_{\infty}\right) \exp \left(b_{2} x\right)
$$

where $b_{2}$ is a positive quantity. Accordingly, the fluid stream temperature surrounding the pin given by Equation (41) is equal to

$$
T_{d}\left(x, x^{\prime}\right)=T_{\infty}+\left(T_{\text {so }}-T_{\infty}\right) \exp \left(b_{2} x-b_{1} x^{\prime}\right)
$$

where $T_{s o}$ is the temperature of the surface opposing the pin left end. In terms of dimensionless variables given by Equation (3a) and Equation (23), Equation (57) changes to

$$
T_{d}\left(x^{*}, t^{*}\right)=T_{\infty}+\left(T_{s o}-T_{\infty}\right) C \exp \left(B_{2}\left[x^{*}+\lambda_{2} t^{*}\right]\right)
$$

where $B_{2}, C$ and $\lambda_{2}$ are equal to

$$
B_{2}=b_{2} L ;
$$




$$
\begin{gathered}
C=\exp \left(-b_{1} x_{o}\right) ; \\
B_{1}=b_{1} L ; \\
\lambda_{2}=\left(B_{1} P e_{f}\right) / B_{2}
\end{gathered}
$$

According to Equation (57), the dimensionless time required for the pin to reach the heated boundary is given by $t_{f}^{*}=x_{o} /\left(L P e_{f}\right)$. Applying the dimensionless variables given by Equation (3a), Equation (44) and Equation (23) on Equation (25) will change it to the following dimensionless form:

$$
\begin{aligned}
& \frac{\partial^{2} \theta}{\partial x^{* 2}}+2 B_{2} \frac{\partial \theta}{\partial x^{*}}-\left[(m L)^{2}-B_{2}^{2}+B_{1} P e_{f}\right] \theta-B_{2}^{2} \\
& +B_{1} P e_{f}=\frac{\partial \theta}{\partial t^{*}}
\end{aligned}
$$

The dimensionless boundaries and initial conditions as adopted in section 2.1 can be expressed in the following dimensionless forms:

$$
\begin{aligned}
& \left.\frac{\partial \theta}{\partial x^{*}}\right|_{x^{*}=0, t^{*}}+B_{2} \theta\left(x^{*}=0, t^{*}\right)=B_{2} ; \\
& \left.\frac{\partial \theta}{\partial x^{*}}\right|_{x^{*}=1, t^{*}}+B_{2} \theta\left(x^{*}=1, t^{*}\right)=B_{2} ; \theta\left(x^{*}, t^{*}=0\right)=1
\end{aligned}
$$

The heat transfer from the pin to the flowing fluid is given by

$$
\begin{aligned}
q_{f-d} & =h P L \int_{0}^{1}\left(T-T_{d}\right) \mathrm{d} x^{*} \\
& =-h P L\left(T_{\text {so }}-T_{\infty}\right) C \int_{0}^{1} \exp \left(B_{2}\left[x^{*}+\lambda_{2} t^{*}\right]\right) \theta \mathrm{d} x^{*}
\end{aligned}
$$

Define the dimensionless pin heat transfer rate $\Theta_{D}$ as the ratio between the pin heat transfer rate to that with maximum temperature difference of $\Delta T_{D}=\left(T_{s o}-T_{\infty}\right)$. Mathematically, it is equal to

$$
\Theta_{D} \equiv \frac{q_{f}}{h P L \Delta T_{D}}=-C \int_{0}^{1} \exp \left(B_{2}\left[x^{*}+\lambda_{2} t^{*}\right]\right) \theta \mathrm{d} x^{*}
$$

\section{Closed Form Solutions}

According to Equation (62), $\Theta_{D}$ is always increasing with time. As such, the maximum value of $\Theta_{D}$, denoted by $\left(\Theta_{D}\right)_{\max }$, is computed at dimensionless time given by $t_{f}^{*}=x_{o} / L$. At that time, $\theta\left(x^{*}, t^{*}\right)$ is expected to be equal to $\theta_{s D}\left(x^{*}\right)$. The solution of $\theta_{s D}\left(x^{*}\right)$ as obtained from solving Equation (60) at large times is equal to

$$
\theta_{s D}\left(x^{*}\right)=C_{7} \exp \left(s_{7} x^{*}\right)+C_{8} \exp \left(s_{8} x^{*}\right)+A_{3}
$$

where $A_{3}, C_{7}, C_{8}, s_{7}$ and $s_{8}$ are equal to

$$
A_{3}=\frac{B_{1} P e_{f}-B_{2}^{2}}{(m L)^{2}+B_{1} P e_{f}-B_{2}^{2}} ;
$$

$$
\begin{gathered}
C_{7}=\left\{\frac{1-A_{3}}{s_{7}+B_{2}}\right\}\left\{\frac{\exp \left(s_{8}\right)-1}{\exp \left(s_{8}\right)-\exp \left(s_{7}\right)}\right\} B_{2} ; \\
C_{8}=\left\{\frac{1-A_{3}}{s_{8}+B_{2}}\right\}\left\{\frac{1-\exp \left(s_{7}\right)}{\exp \left(s_{8}\right)-\exp \left(s_{7}\right)}\right\} B_{2} ; \\
s_{7}=-B_{2}-\sqrt{(m L)^{2}+B_{1} P e_{f}} ; \\
s_{8}=-B_{2}+\sqrt{(m L)^{2}+B_{1} P e_{f}} ;
\end{gathered}
$$

As such, $\left(\Theta_{D}\right)_{\max }$ is equal to

$$
\begin{aligned}
\left(\Theta_{D}\right)_{\max }= & \left\{\frac{1-\exp \left(s_{7}+B_{2}\right)}{s_{7}+B_{2}}\right\} C_{7}+\left\{\frac{1-\exp \left(s_{8}+B_{2}\right)}{s_{8}+B_{2}}\right\} C_{8} \\
& +\left\{\frac{1-\exp \left(B_{2}\right)}{B_{2}}\right\} A_{3}
\end{aligned}
$$

Equation (66) is reducible to the following expression:

$$
\left(\Theta_{D}\right)_{\max }=-\left(\frac{B_{1} P e_{f}}{(m L)^{2}+B_{1} P e_{f}}\right)\left(\frac{\exp \left(B_{2}\right)-1}{B_{2}}\right)
$$

The maximum effective swimming pin index denoted by $m_{\infty}$ can be obtained by solving the following equation: $\left.q_{f-d}\right|_{m=m_{\infty}}=\left.0.99 q_{f-d}\right|_{m \rightarrow \infty}$. As such, the dimensionless effective length for this case $m_{\infty} L$ can be obtained to be equal to $m_{\infty} L=9.95 \sqrt{B_{1} P e_{f}}$.

\subsection{Effective Thermal Conductivity for the Fluid Loaded With Swimming Pins of Kind (A)}

Suppose that the pin volume fraction is equal to $\varphi=n_{f} V_{s f} / V$ where $n_{f}$ is the number of swimming pins, $V_{s f}$ is the volume of a single pin and $V$ is the fluid volume. The maximum value of $\varphi$ is taken to be $1.5 \%$ which is expected to cause insignificant effect on the fluid flow pressure drop $[5,19]$. The net heat flux received by the fluid can be shown to be equal to

$$
q_{d}^{\prime \prime}=q_{s}^{\prime \prime}+\varphi\left(\frac{A_{C o}}{A_{C}}\right)\left(\frac{q_{f-d}}{P_{o} L}\right)=\left.k \frac{\partial T_{d}}{\partial r}\right|_{r=r_{o}}
$$

where $A_{C o}, k$ and $r$ are the pipe cross-sectional area $\left(A_{C}=\pi r_{o}^{2}\right)$, fluid thermal conductivity and the pipe radial coordinate, respectively. For homogenous mixture of the swimming pins and the pure fluid, the mixture can be approximated as a continuum fluid with effective thermal conductivity $k_{\text {effA }}$. For this case, the boundary heat flux, $q_{s}^{\prime \prime}$, is given by 


$$
q_{s}^{\prime \prime}=\left.k_{e f f A} \frac{\partial T_{d}}{\partial r}\right|_{r=r_{o}}
$$

By solving Eqs. (68) and (69) simultaneously, $k_{\text {effA }}$ can be obtained and it is equal to

$$
\frac{k_{e f f A}}{k}=\left[1+2 \varphi\left(\frac{k_{f}}{k}\right)\left(\frac{r_{o}}{L}\right) \frac{(m L)^{2}}{P e_{A}} \Theta_{A}\right]^{-1}
$$

where $P e_{A}$ is the pure fluid Peclet number;

$P e_{A}=\rho c_{p} u_{m} 2 r_{o} / k$. Note that $u_{m}$ is the pure fluid mean velocity.

\subsection{Effective Thermal Conductivity for the Fluid Loaded With Swimming Pins of Kind (B)}

The steady state rate of heat transfer through the pin is independent on the pin speed. As such, the effective thermal conductivity can be obtained by equating the transverse conduction across a given volume of fluid and swimming pins $\left(V=A_{C o} L\right)$ to that across a homogenous mixture with effective thermal conductivity $k_{\text {effB }}$ under the same temperature difference. Mathematically, this energy balance is given by

$$
k A_{C o}(1-\varphi) \frac{\Delta T_{d}}{L}+\varphi\left[\frac{A_{C o}}{A_{C}}\right] \gamma h P L \Delta T_{d}=k_{e f f B} A_{C o} \frac{\Delta T_{d}}{L}
$$

As such, $k_{\text {effB }}$ is given by:

$$
\frac{k_{e f f B}}{k}=(1-\varphi)+\varphi\left(\frac{k_{f}}{k}\right)\left\{1-\frac{1}{\cosh (m L / 2)}\right\}
$$

Based on effective pin length, Equation (72) is reducible to

$$
\frac{k_{e f f B}}{k}=(1-\varphi)+0.99 \varphi\left(\frac{k_{f}}{k}\right)
$$

\subsection{Effective Thermal Conductivity for the Fluid Loaded With Swimming Pins of Kind (C)}

The rate of heat transfer from the heated surface (per unit cross-sectional area normal to $x$ '-axis) is given by:

$$
\begin{aligned}
q_{d}^{\prime \prime} & =\left.k \frac{\mathrm{d} T_{d}}{\mathrm{~d} x^{\prime}}\right|_{x^{\prime}=0}(1-\varphi)-\varphi\left(\frac{1}{A_{C}}\right)\left(q_{f-d}\right)_{\max } \\
& =-\left.k_{\text {effC }} \frac{\mathrm{d} T_{d}}{\mathrm{~d} x^{\prime}}\right|_{x^{\prime}=0}
\end{aligned}
$$

As such, $k_{\text {effC }}$ can be obtained and it is equal to

$$
\frac{k_{e f f C}}{k}=(1-\varphi)-\frac{\varphi(m L)^{2}}{B}\left(\frac{k_{f}}{k}\right)\left(\Theta_{C}\right)_{\max }
$$

\subsection{Effective Thermal Conductivity for the Fluid Loaded With Swimming Pins of Kind (D)}

The rate of heat transfer from the heated surface (per unit cross-sectional area normal to $x$ '-axis) is given by:

$$
\begin{aligned}
& -(1-\varphi) k \int_{0}^{1}\left(\left.\frac{\partial T_{d}}{\partial x^{\prime}}\right|_{x^{\prime}=0}\right) \mathrm{d} x^{*}-\varphi\left(\frac{1}{A_{C}}\right) q_{f-d} \\
& =-k_{e f f D} \int_{0}^{1}\left(\left.\frac{\partial T_{d}}{\partial x^{\prime}}\right|_{x^{\prime}=0}\right) \mathrm{d} x^{*}
\end{aligned}
$$

Therefore, $k_{\text {effD }}$ can be obtained and it is equal to

$$
\frac{k_{e f f D}}{k}=(1-\varphi)+\varphi\left(\frac{k_{f}}{k}\right)\left(\frac{(m L)^{2}}{(m L)^{2}+B_{1} P e_{f}}\right) P e_{f}
$$

Based on maximum effective pin index, Equation (76) is reducible to

$$
\frac{k_{e f f D}}{k}=(1-\varphi)+0.99 \varphi\left(\frac{k_{f}}{k}\right) P e_{f}
$$

\section{Discussion of the Results}

Figure 3 shows the variation of the dimensionless rate of heat transferred from the fluid to the pin $-\Theta_{A}$ with the pin thermal length $m L$, pin Peclet number $P e_{f}$ and dimensionless time $t^{*}$ for case A-swimming pins. Heat transfer to the swimming pin is expected to increase as $m L$ increases however, the dominator of Equation (8) increases largely with the increase of $h P L$. The latter quaintly increases linearly with $(m L)^{2}$. As such, $-\Theta_{A}$ is shown to decrease as $m L$ increases. The initial value of $-\Theta_{A}$ is found from Figure 3 to be equal to 0.5. This value coincides with the value obtained by integrating Equation $(11 \mathrm{c})$ over the whole range of $x^{*}$ as given by Equation (8). This validates the obtained closed form solutions. As $t^{*}$ increases, $-\Theta_{A}$ is found to increase at lower values of $m L$ while at large values of $m L,-\Theta_{A}$ is unaffected with the time variable. Increasing the value of $P e_{f}$ causes an increase in $-\Theta_{A}$. This is because pins swimming at larger $U$-values (larger $P e_{f}$-values) reach to the fluid volumes with larger temperatures in a shorter period of time. Thus, the temperature difference between the fluid and the pin increases causing an increase in the rate of the heat transfer to the pin.

Factors that increases the convection heat transfer to the pin such as increasing the values of $P e_{f}$ and $m L$ and 


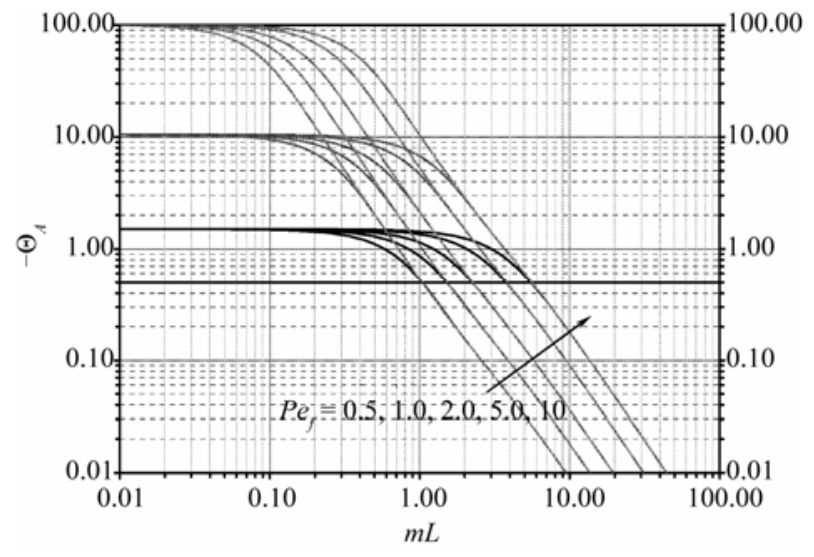

Figure 3. Effects of $m L, P e_{f}$ and $t^{*}$ on $\Theta_{A}$.

decreasing the time variable $t^{*}$ tend to increases the effective thermal conductivity, $k_{\text {effA }}$, of the flu$\mathrm{id} /$ swimming-pins system. These trends are quite recognizable in Figure 4. It can be recommended from Figure 4 to have swimming pins with $m L>10$ so that $k_{\text {effa }}$ be less sensitive to the variation of $m L$. Figure 5 shows the variation of the performance indicator $\gamma$ and effective thermal conductivity of the fluid/swimming-pins system, $k_{\text {effB }}$, with the pin thermal length $m L$ for case $\mathrm{B}$-swimming pins. It is noticed that the values of $\gamma$ is almost independent on $m L$ when $m L<0.65$. In addition, it can be noticed that $k_{\text {effB }}$ increases as $m L$ increases until it becomes independent on $m L$ when $m L>11$. Moreover, it can be seen that as the swimming pins volume ratio increases, the effective thermal conductivity $k_{\text {effB }}$ increases.

Figure 6 shows the effects of the pin thermal length $m L$, pin Peclet number $P e_{f}$ and dimensionless fluid temperature variation index $B$ on the maximum dimensionless rate of heat transferred from the fluid to the pin $-\left(\Theta_{C}\right)_{\max }$ for case C-swimming pins. The role of $m L$ and $P e_{f}$ on $-\left(\Theta_{C}\right)_{\max }$ is similar to their role on $-\Theta_{A}$ which are discussed previously. For small $B$-values, the pin encounters a larger temperature difference between its temperature and the fluid temperature for a larger period of time as compared to cases with larger $B$-values. Thus, heat transfer to the swimming pin is expected to increase as $B$ decreases. As such, $-\left(\Theta_{C}\right)_{\max }$ increases as $B$ decreases. The effective thermal conductivity $k_{\text {effC }}$ is found to be highly affected by $P e_{f}$ and less affected by $B$ at large $m L$-values as can be seen from Figure 7. According to this figure, the values of the effective thermal conductivity $k_{\text {effC }}$ can be larger than those for $k_{\text {effA }}$ and $k_{\text {effB }}$ at the same $m L$-values. Figure 8 shows that the case D-swimming pin maximum heat transfer is highly affected by the fluid temperature increase along the pin length. However, the effective thermal conductivity of the fluid/swimming-pins system, $k_{\text {effD }}$, is noticed to be independent on that temperature increase as given by

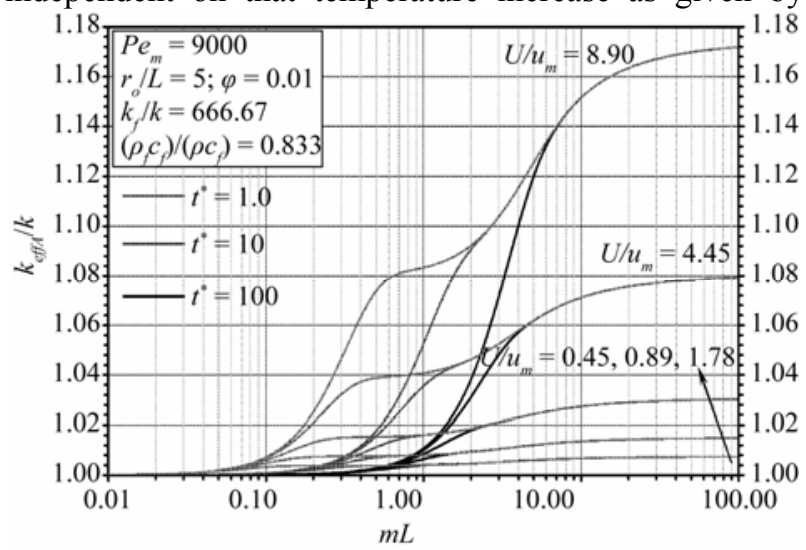

Figure 4. Effects of $m L, U / u_{m}$ and $t^{*}$ on $k_{\text {effA }} / k$.

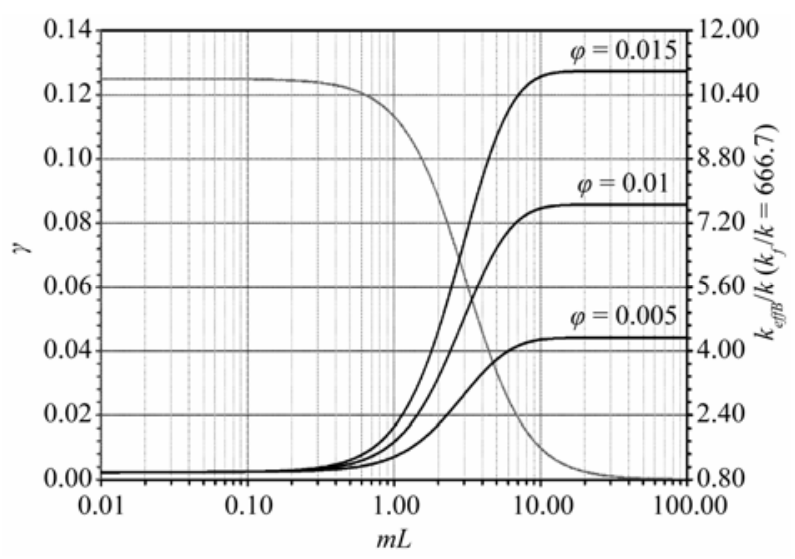

Figure 5. Effects of $m L$ on $\gamma$ an, $m L$ and $\varphi$ on $k_{e f f B} / k$.

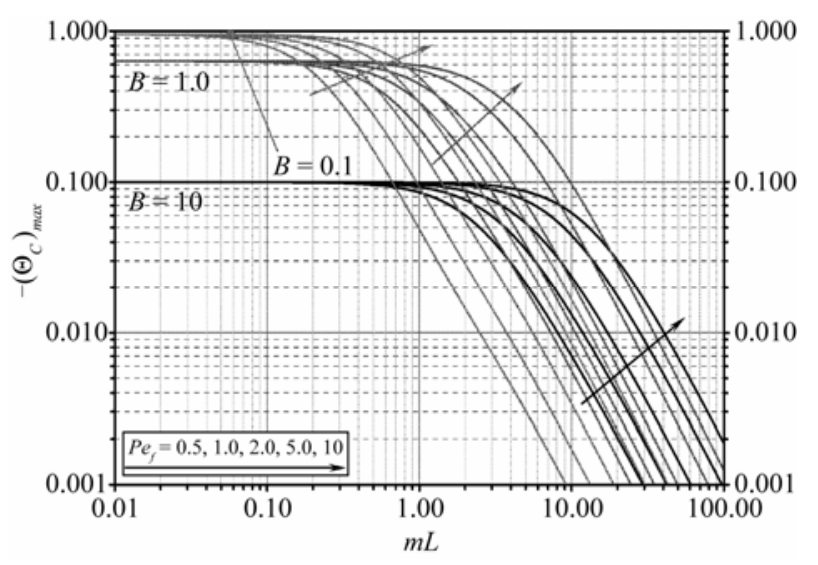

Figure 6. Effects of $m L, P e_{f}$ and $B$ on $-\left(\Theta_{C}\right)_{\max }$.

Equation (77) and seen from Figure 9. According to Figure 10, it is noticed that the maximum dimensionless effective pin index $m_{\infty} L$ is always larger than 95 and that the values of $m_{\infty} L$ correspond to case $\mathrm{C}$ is always greater than those correspond to case A.

Furthermore, the values of $m_{\infty} L$ of case $\mathrm{C}$ decreases as 
$B$ decreases and it converges to the values of $m_{\infty} L$ of case

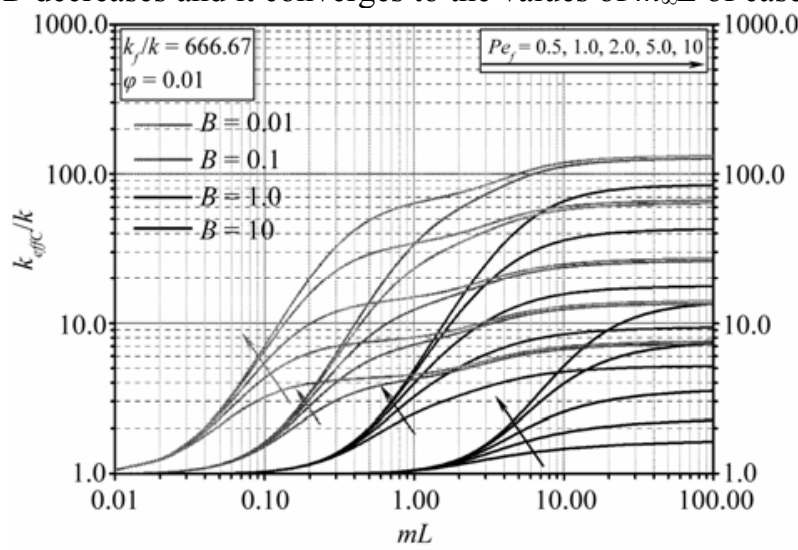

Figure 7. Effects of $m L$ on $\gamma$ an, $m L$ and $\varphi$ on $k_{\text {effB }} / k$.

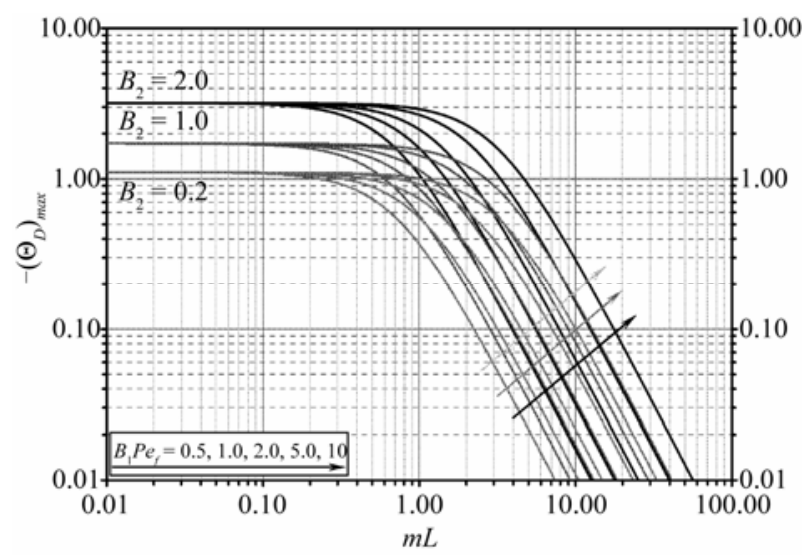

Figure 8. Effects of $m L, P e_{f}$ and $B_{2}$ on $\left(\Theta_{D}\right)_{\max }$.

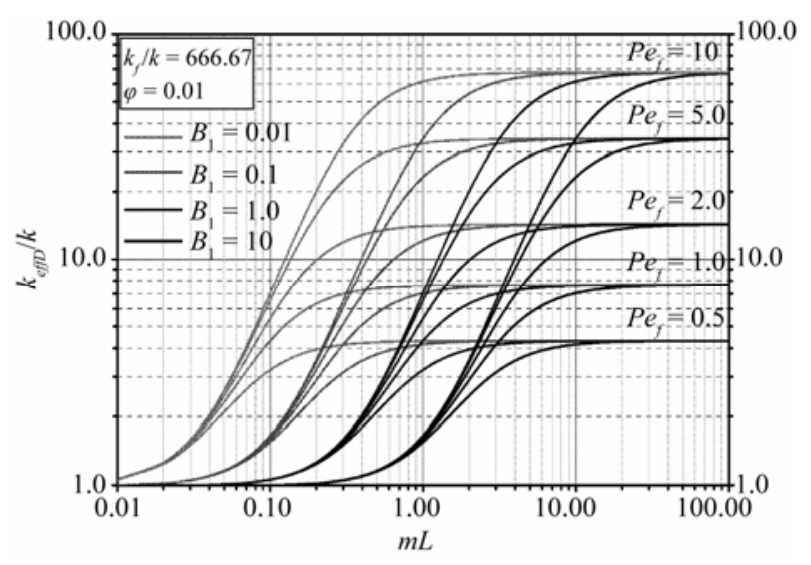

Figure 9. Effects of $m L, P e_{f}$ and $B_{1}$ on $k_{e f f D} / k$.

A as B approaches zero.

\section{Conclusions}

In this work, heat transfer to pins swimming inside no-isothermal fluid was theoretically analyzed. Four dif- ferent types of swimming pins were considered: [A] Pins

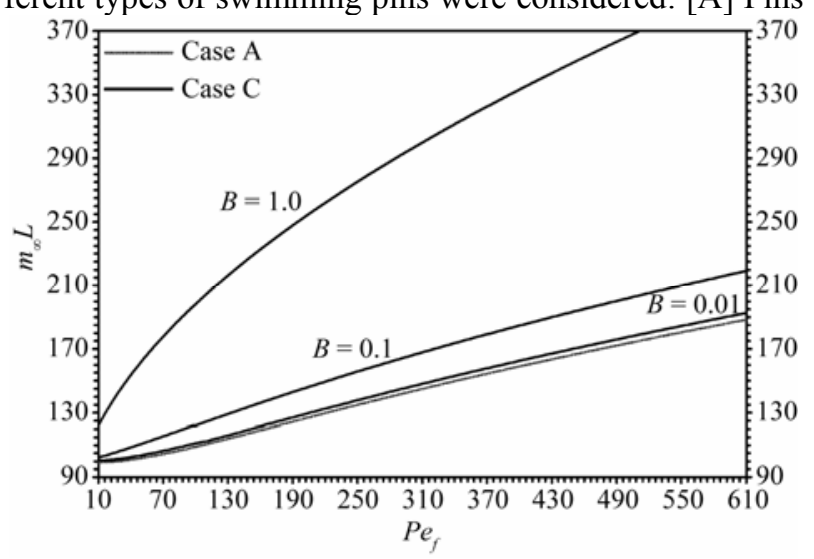

Figure 10. Effects of $P e_{f}$ and $B$ on $m_{\infty} L$.

swimming longitudinally in flowing fluid having constant temperature gradient, [B] Pins aligned transversely and swimming in flowing fluid having constant temperature gradient, [C] Pins swimming longitudinally towards a heated surface, and [D] Pins moving transversely towards the heated surface. Appropriate unsteady energy transport equations were identified, dimesionlaized and solved theoretically. Closed form solutions for the pin temperature and the heat transfer rates to the pins or through the pins were obtained for each case. Accordingly, the effective thermal conductivities of the fluid/ swimming-pins systems were computed.

The following main findings were reported:

- Heat transfer to the swimming pin increases as the pin thermal length increases.

- Heat transfer to the swimming pin increases as the pin Peclet number increases.

- Heat transfer to the swimming pin increases as the fluid temperature index decreases.

- Heat transfer to the swimming pin increases as the temperature difference along the pin length increases.

- The fluid/swimming-pins system effective thermal conductivity increases as both pin thermal length and Peclet number increase.

- It can be recommended that swimming pins of case A have thermal lengths larger than 10 so that the system effective thermal conductivity be less responsive to the thermal length.

- Swimming pins of case B with thermal lengths larger than 11 produce system effective thermal conductivity independent on the variation of the thermal length.

- Swimming pins of case C produces system effective thermal conductivities larger than those of cases A and $\mathrm{B}$. This trend agrees with the finding of Khaled and Vafai [23] that boundary arrangement of the dispersive elements produce substantial enhancements in heat transfer compared to other arrangements. 
- Swimming pins of case D produces system effective thermal conductivities independent on temperature difference along the pin length.

Finally, the closed form solutions derived in this work can form a basis for constructing and modeling super convective fluidic systems that can be used in cooling of electronic components.

\section{Acknowledgments}

The support of this work by King Abdulaziz City for Science and Technology (KACST) under project no. 8-ENE192-3 is acknowledged.

\section{References}

[1] W. M. Kays, "Pin-Fin Heat-exchanger Surfaces," Journal of Heat Transfer-Transactions of the ASME, Vol. 77, 1955, pp. 471-483.

[2] D. O. Kern and A. D. Kraus, "Extended Surface Heat Transfer", McGraw-Hill, New York, 1972.

[3] A. D. Kraus, A. Aziz, and J. R. Welty, "Extended Surface Heat Transfer," John Wiley \& Sons, Inc. New York, 2001.

[4] A. Nuntaphan, T. Kiatsiriroat and C. C. Wang, "Air Side Performance at Low Reynolds Number of Cross-flow Heat Exchanger using Crimped Spiral Fins," International Communications in Heat and Mass Transfer, Vol. 32 , No. 1-2, 2005, pp. 151-165. doi:10.1016/j.icheatmasstransfer.2004.03.022

[5] X. -Q. Wang and A. S. Mujumdar, "Heat Transfer Characteristics of Nanofluids: A Review," International Journal of Thermal Sciences, Vol. 46, No. 1, 2007, pp. 1-19. doi:10.1016/j.ijthermalsci.2006.06.010

[6] A. E. Bergles, "Handbook of Heat Transfer," $3^{\text {rd }}$ Edition, McGraw-Hill, New York, 1998, pp. 11.1-11.76.

[7] D. -K. Yang, K. -S. Lee and S. Song, "Fin Spacing Optimization of a Fin-tube Heat Exchanger Under Frosting Conditions," International Journal of Heat and Mass transfer, Vol. 49, No. 15-16, 2006, pp. 2619-2625. doi:10.1016/j.ijheatmasstransfer.2006.01.016

[8] N. Sahiti, A. Lemouedda, D. Stojkovic, F. Durst and S. Franz, "Performance Comparison of Pin Fin In-duct Flow Arrays with Various Pin Cross-sections," Applied Thermal Engineering, Vol. 26, No. 11-12, 2006, pp. 11761192. doi:10.1016/j.applthermaleng.2005.10.042

[9] M. Almogbel and A. Bejan, "Cylindrical Trees of Pin Fin," International Journal of Heat and Mass Transfer, Vol. 43, No. 23, 2000, pp. 4285-4297. doi:10.1016/S0017-9310(00)00049-1

[10] M. Almogbel, "Constructal Tree-Shaped Fins," International Journal of Thermal Sciences, Vol. 44, No. 4, 2005, pp. 342-348. doi:10.1016/j.ijthermalsci.2004.11.002
[11] L. Li, W. Cui, Q. Liao, X. Mingdao, T-C. Jen, Q. Chen, "Heat Transfer Augmentation in 3D Internally Finned and Microfinned Helical Tube," International Journal of Heat and Mass Transfer, Vol. 48, 2005, pp. 1916-1925. doi:10.1016/j.ijheatmasstransfer.2004.12.003

[12] S. Kiwan and M. A. Al-Nimr, "Using Porous Fin for Heat Transfer Enhancement," Journal of Heat Transfer-Transactions of the ASME, Vol. 123, No. 4, 2001, pp. 617-623. doi:10.1115/1.1371922

[13] T. K. Aldoss, M. A. Al-Nimr and M. Hader, "Using Capsulated Liquid Metal Fins for Heat Transfer Enhancement," Journal of Enhanced Heat Transfer, Vol. 11, No. 2, 2004, pp. 151-160.

doi:10.1615/JEnhHeatTransf.v11.i2.40

[14] A. -R. A. Khaled, "Maximizing Heat Transfer through Joint Fin Systems," Journal of Heat Transfer-Transactions of the ASME, Vol. 128, No. 2, 2006, pp. 203-206. doi:10.1115/1.2137764

[15] A. -R. A. Khaled, "Investigation of Heat Transfer Enhancement Using Permeable Fins," Journal of Heat Transfer-Transactions of ASME, Vol. 132, No. 3, 2010, pp. 1-5. doi:10.1115/1.4000056

[16] A. -R. A. Khaled, "Heat Transfer Analysis through Solar and Rooted Fins," Journal of Heat Transfer-Transactions of the ASME, Vol. 130, No. 8, 2008, Article no. 74503, pp. 1-4.

[17] A. -R. A. Khaled, "Thermal Characterizations of Fin-Thin Film Systems," Journal of Heat Transfer-Transactions of the ASME, Vol. 132, No. 10, 2010, pp. 1-6. doi:10.1115/1.4001647

[18] J. A. Eastman, S. U. S. Choi, S. Li, W. Yu and L. J. Thompson, "Anomalously Increased Effective Thermal Conductivities of Ethylene Glycol-based Nanofluids Containing Copper Nanoparticles," Applied Physics Letters, Vol. 78, No. 6, 2001, pp. 718-720. doi:10.1063/1.1341218

[19] Y. Xuan and Q. Li, "Investigation on Convective Heat Transfer and Flow Features of Nanofluids," Journal of Heat Transfer - Transactions of the ASME, Vol. 125, No. 1, 2003, pp. 151-155.doi:10.1115/1.1532008

[20] M. Siddique, A. -R. A.Khaled, N. I. Abdulhafiz and A. Y. Boukhary, "Recent Advances in Heat Transfer Enhancements: A Review Report," International Journal of Chemical Engineering, Vol. 2010, Article ID 106461, 2010, pp.1-28. doi:10.1155/2010/106461

[21] F. P. Incorpera, D. P. DeWitt, T. L. Bergman, and A. S. Lavine, "Fundamentals of Heat and Mass Transfer- $6^{\text {th }}$ Edition," John Wiley, New York, 2006.

[22] M. N. Ozisik, "Heat Conduction," $2^{\text {nd }}$ edition, John Wiley \& Sons, Inc., New York, 1993.

[23] A. -R. A. Khaled and K. Vafai, "Heat Transfer through Control of Thermal Dispersion Effects," International Journal of Heat and Mass Transfer, Vol. 48, No. 11, 2005 , pp. $2172-2185$.

doi:10.1016/j.ijheatmasstransfer.2004.12.035 


\section{Nomenclature}

$A_{1}-A_{3} \quad$ steady state particular solutions; Equations (17a), (53a) \& (65a)

$A_{C} \quad$ pin cross-sectional area

$A_{\text {Co }} \quad$ pipe cross-sectional area

$B, B_{1}, B_{2}$ exponential functions dimensionless indices

$b, b_{1}, b_{2}$ exponential functions indices

$C_{1}-C_{8} \quad$ steady state general solutions coefficients; Equations $(17 b, c),(53 b, c) \&(65 b, c)$

$c_{p} \quad$ pure fluid specific heat $[\mathrm{J} / \mathrm{kgK}]$

$E_{a}, E_{n}$ homogenous solution coefficients; Equation (19a, b)

$F_{n} \quad$ homogenous solution coefficients; Equation (37)

$g$ transformed dimensionless temperature; Equation (9) \& Equation (31)

$g_{s} \quad$ transformed dimensionless steady state temperature; Equation (12) \& Equation (35)

$h$ convection heat transfer coefficient between the pin and the fluid $\left[\mathrm{W} / \mathrm{m}^{2} \mathrm{~K}\right]$

$k \quad$ pure fluid thermal conductivity [W/m.K]

$k_{\text {eff }} \quad$ Effective fluid-swimming pins thermal conductivity; Equation (70), (72), (75) \& (77)

$k_{f} \quad$ pin thermal conductivity $[\mathrm{W} / \mathrm{m} . \mathrm{K}]$

$L \quad$ pin length $[m]$

$m \quad$ pin index $[m]$

$n \quad$ Integer $(n=1,2,3, \cdots, \infty)$

$n_{f} \quad$ number of swimming pins

$P e_{A} \quad$ Peclet number for case A $\left(P e_{A}=\rho c p u_{m} 2 r_{o} / k\right)$

$P e_{f} \quad$ pin Peclet number $\left(P e_{f}=\rho_{f} C_{f} U L / k_{f}\right)$

$q_{f-d} \quad$ total convection heat transfer rate from the pin to the fluid $[W]$

$q_{f} \quad$ pin maximum conduction heat transfer rate $[W]$

$r \quad$ radius axis $[m]$

$r_{o} \quad$ inner radius of the pipe $[\mathrm{m}]$

$S_{1}-S_{8} \quad$ steady state general solutions exponential dimensionless indices; Equations 17(d, e), 53(d, e) $\& 65(\mathrm{~d}, \mathrm{e})$

$T_{d} \quad$ pin surrounding fluid temperature $[K]$

$T_{d, i} \quad$ pin surrounding fluid temperature at the pipe inlet $[K]$

$T_{f} \quad$ pin temperature $[K]$

$T_{s} \quad$ heated surface temperature $[K]$

$T_{\text {so }} \quad$ reference heated surface temperature $[K]$

$T_{\infty} \quad$ outer fluid free stream temperature $[K]$

$t \quad$ time variable [s]

$t^{*} \quad$ Dimensionless time; Equation (3b) \& Equation (23)

$U \quad$ swimming pin velocity $[\mathrm{m} / \mathrm{s}]$

$u_{m} \quad$ Mean fluid velocity inside the pipe for cases (A) and (B) $[\mathrm{m} / \mathrm{s}]$

$V \quad$ Fluid and swimming pins volume per pin length $\left(V=A_{C o} L\right)$

$V_{s f} \quad$ Volume of single pin $\left(V_{s f}=A_{C} L\right)$

$X \quad$ pin axial coordinate $[m]$

$x^{\prime} \quad$ pin leading edge position vector $[\mathrm{m}]$

$x_{O} \quad$ pin leading edge initial position vector $[\mathrm{m}]$

$x^{*} \quad$ dimensionless $x$-coordinate $\left(x^{*}=x / L\right)$

\section{Greek symbols}

$\Theta \quad$ dimensionless pin convection heat transfer; Equations (8), (30), (48) \& (63)

$\phi_{1}, \phi_{2} \quad$ characteristic functions; Equation (5c) \& Equation (27a)

$\gamma \quad$ pin maximum dimensionless conduction heat transfer for case B; Equation (40)

$\varphi \quad$ Swimming pins to fluid volume ratio $\left(\varphi=n_{f} V_{s f} / V\right)$

$\lambda_{1}, \lambda_{2} \quad$ pin to fluid temperature difference ratios times pin Peclet number; Equations (27b) (59d)

$\theta$ pin dimensionless temperature; Equation (3c) \& Equation (44)

$\rho \quad$ inner fluid density $\left[\mathrm{kg} / \mathrm{m}^{3}\right]$

$\psi \quad$ homogenous solution; Equation (16) \& Equation (36)

\section{Subscripts}

$\begin{array}{ll}A, B, C, D & \text { cases } \mathrm{A}, \mathrm{B}, \mathrm{C} \text { and } \mathrm{D} \\ \mathrm{S} & \text { steady state }\end{array}$

